\title{
Spatial list learning in black-capped chickadees
}

\author{
JONATHON D. CRYSTAL and SARA J. SHETTLEWORTH \\ University of Toronto, Toronto, Ontario, Canada
}

\begin{abstract}
Black-capped chickadees (Parus atricapillus), a food-storing bird, were presented with threeitem lists of unique spatial configurations. Each item consisted of one baited and three nonbaited feeders. Memory for the location of the hidden bait in each configuration was tested. Both primacy and recency effects were observed. The results from this use of a new species and procedure provide further evidence for the generality of serial position effects in animals.
\end{abstract}

One approach to the study of animal cognition is to investigate the relationship between the natural history of animals and their cognitive abilities (e.g., Balda \& Kamil, 1989). A second approach is to elucidate cognitive processes more abstractly (e.g., Hitch, 1985; for discussion, see Shettleworth, 1993; Staddon, 1989). The gap between these two approaches may be bridged by investigating phenomena of global importance to cognition while selecting species in which the exploration of such phenomena is particularly interesting (Kamil, 1988). The serial position effect is a good candidate for such a project. In many settings, information is acquired in a sequence, with early and late events remembered better than intermediate events. Enhanced memory for early and late information is referred to as the primacy and recency effects, respectively. Such serial position effects have been demonstrated in a number of species in addition to humans, including monkeys, pigeons, and rats (for reviews of human and nonhuman animal research, see Crowder, 1976, and Wright, 1989, respectively), suggesting that a general cognitive process may be responsible for these phenomena.

A useful technique for investigating serial position effects in nonhuman animals is serial probe recognition (SPR) (Santiago \& Wright, 1984; Wright, Santiago, Sands, Kendrick, \& Cook, 1985). A list of to-beremembered items is presented to the subject, following which the subject is required to indicate whether a test item (probe) was in the list (old) or not (new). With relatively short retention intervals between the last list item

This research was supported by the Natural Sciences and Engineering Research Council of Canada (NSERC) through an Undergraduate Research Award to the first author and a research grant to the second. The research is based on a BSc thesis submitted to the Department of Psychology at the University of Toronto and presented to the 22nd annual Ontario Undergraduate Thesis Conference on May 1, 1992, by J. D. Crystal. We thank Dave Brodbeck, Rick Westwood, Andrew Gristock, and Mike Child for assistance and Ken Cheng, Rob Hampton, Dave Brodbeck, and an anonymous reviewer for comments on a previous draft of the manuscript. J. D. Crystal is now at Brown University. Requests for reprints may be addressed to S. J. Shettleworth, Department of Psychology, University of Toronto, Toronto, ON M5S 1A1, Canada (email: shettle@psych.toronto.edu). and the probe, a strong recency effect is observed in monkeys, pigeons, and humans. With relatively long retention intervals, a prominent primacy effect is found. At intermediate delays, both primacy and recency effects occur (Wright et al., 1985). Similar results have been observed with rats in the radial maze (see, e.g., Bolhuis \& van Kampen, 1988).

Whereas the performance of humans, monkeys, pigeons, and rats produces serial position curves, foodstoring birds recovering stored food do not consistently show this pattern (Sherry, 1984b; Vander Wall, 1990). This suggests that either the underlying mechanism is different in these birds or the task is sufficiently different to preclude detection of serial position effects. Blackcapped chickadees (Parus atricapillus) may store hundreds of food items per day in scattered caches and appear to recover these within a day or two by using memory (for reviews see Kamil \& Balda, 1990b; Sherry, 1984b; Shettleworth, 1990). In laboratory tests, they are able to remember the locations of caches for at least 14 days (Hitchcock \& Sherry, 1990). Such apparently capacious and long-lasting memory, taken together with the natural history of food storers, suggests that their memory may be adaptively specialized (Shettleworth, 1990).

The serial position effect has been examined in foodstoring birds through observation of the sequence in which birds recover their caches (e.g., Sherry, 1982; Shettleworth \& Krebs, 1982). Primacy is demonstrated when food is recovered in the same order as that in which it was cached. Recency is indicated by recovery in the reverse order. Although primacy and recency are usually demonstrated by differential accuracy as a function of serial position, it seems reasonable that the best remembered items will be recovered first. Indeed, Kamil and Balda (1990a) have shown this to be true for Clark's nutcrackers.

Because the probability that a cache has been discovered by another animal increases with time, cache recovery success in the wild may be maximized by the use of a recency strategy (Shettleworth \& Krebs, 1982). This optimality hypothesis argues against a primacy effect for food-storing birds in recovery of stored food. A further reason to suspect that food-storing birds may not demon- 
strate primacy and recency effects stems from consideration of the interference theory account of the serial position effect (Wright, 1989). Interference theory proposes that retroactive interference and proactive interference produce recency and primacy effects, respectively. Foodstoring birds would benefit if they were resistant to such interference and so could remember many locations for long durations (Shettleworth, 1990).

Because the expression of primacy and recency effects depends on the length of retention interval, however, the particular intervals used in previous studies may explain the observed inconsistencies. Vander Wall (1990) points out that inconsistent results in sequential recovery patterns may also stem from the confounding influence of minimizing travel time between stored items. This suggests that a procedure that controls the order of recovery may be more sensitive in detecting primacy and recency. Under such circumstances, the level of correct performance rather than recovery order may be used to evaluate primacy and recency in a way more analogous to that employed in other studies of the serial position effect. Kamil, Balda, Olson, and Good (1993), using such a test, found no relationship between cache order and memory for individual caches by nutcrackers. It is difficult to interpret this result, however, because although the experimenters controlled recovery order, the birds controlled caching order.

Primacy and/or recency effects have been observed in storing species performing nonstoring spatial working memory tasks (see, e.g., Basil, 1992; Hilton \& Krebs, 1990; Olson, 1991). For example, in four species of parids, revisiting errors were least likely in the first and last arms on an open-field analogue of a radial maze (Hilton \& Krebs, 1990). Some investigators (Hilton \& Krebs, 1990; Olson, 1991) have varied the retention interval to see whether that would affect the shape of the serial position curve. However, no effects like those reported by Wright et al. (1985) have been observed.

However, radial maze and spatial delayed nonmatching tasks capture only one aspect of the food-storing situation-namely, avoiding revisits to sites from which food has already been retrieved (Shettleworth, 1985). To remember where it put food in the first place, a bird must encode information about many unique sites on the basis of a single, brief visit to each one. A task that captures this feature of food storing is the one-trial associative memory task used by Brodbeck, Burack, and Shettleworth (1992; see also Healy \& Krebs, 1992). In this task, chickadees are released into an aviary with wood blocks hanging on the walls. One block is baited with a peanut. The bird is allowed to eat some of the peanut before being returned to its cage for a short retention interval. When the bird is returned to the aviary, the holes on the blocks are covered, thereby concealing their contents, and the birds are required to find the hidden peanut. This task may be construed as consisting of one spatial item. The item itself is the location of the peanut within the spatial array of feeders. Memory for sites at which food has been encountered in this way appears to be subserved by the same memory system as does memory for locations of stored food. For example, tests in which some items are stored while others are encountered in the manner described above have not revealed any differences in subsequent retrieval of the two types of items (Brodbeck, in press; Shettleworth, Krebs, Healy, \& Thomas, 1990).

The purpose of the research reported here, then, was to determine whether a serial position effect in memory for food locations could be found in a species of foodstoring bird, the black-capped chickadee, in a task with demands similar to cache recovery. The birds were required to maintain in memory three spatial items by allowing them to encounter three spatial arrays in sequence. After a retention interval, a bird was permitted to recover the food from each array, with the order of recovery (i.e., Item 1, 2, or 3) controlled by the experimenter. Data from the first recovery test of each session are comparable to those generated by serial probe recognition. If foodstoring black-capped chickadees are resistant to interitem interference, then better-than-chance performance is expected in each serial position of a three-item list with no serial position effect. In contrast, if serial position effects are a general feature of animal memory, then such effects might be found even in a species with a "specialized" memory. Data from the first configuration tested were the primary data, because data from SPR consist of only one test (see, e.g., Wright, 1989). However, data from the second and third tests were also examined. Consistency across consecutive tests would indicate that the tests themselves do not interfere with item memory (i.e., low output interference).

\section{METHOD}

\section{Subjects}

Five black-capped chickadees, Parus atricapillus, caught at the Erindale campus, University of Toronto, served as subjects. Two chickadees $(91-19,91-20)$ were experimentally naive. The other 3 had participated in a food-storing version of the food-finding task employed here (Brodbeck, in press) but without the memory load requirement. Each bird was individually housed in a room maintained on a 10.5:13.5 light:dark cycle, adjacent to the experimental aviary described below. The birds were deprived of food overnight and until the session began $2 \mathrm{~h}$ after light onset. Food was returned to the cages at the end of the session, which lasted approximately $2.5 \mathrm{~h}$.

\section{Aviary}

An observation window protruded $38.1 \mathrm{~cm}$ into the aviary. Birds were able to fly from their cages into the aviary through a trap door located $64.3 \mathrm{~cm}$ to the left of the observation window. The wall (3.51 m long $\times 2.25 \mathrm{~m}$ high) opposite the door, the two sidewalls (each $2.43 \mathrm{~m}$ long), and the ceiling were covered with wire mesh on which wooden feeders could be suspended. The aviary contained a platform placed in front of the trap door and, after the training phase, three artificial trees and six cardboard posters suspended on the walls and ceiling. The trees and posters were in fixed locations throughout the experiment. Each tree $(184 \mathrm{~cm}$ high) was constructed and painted differently and had eight board branches $(57 \mathrm{~cm}$ 
long) sticking out at right angles from the central trunk. The top six branches were used to suspend feeders at the distal ends of the branches, each of which pointed in a unique compass direction.

The wall opposite the door was divided into six $58.4-\mathrm{cm}$ columns and ten $20.3-\mathrm{cm}$ rows; the two sidewalls were each divided into four $61.1-\mathrm{cm}$ columns and 10 rows. The top eight rows were used to suspend feeders. This partitioning defined a $14 \times 8$ coordinate system on which feeders were placed. Thus, there were 112 and 18 possible locations where a feeder could be positioned on the walls and trees, respectively. Each feeder $(8.3 \mathrm{~cm}$ wide, $12.7 \mathrm{~cm}$ high, $3.8 \mathrm{~cm}$ thick) was painted with a unique pattern, had a $5.5-\mathrm{cm}$ dowel protruding $3.6 \mathrm{~cm}$ from the bottom of the block, and had a 0.6 $\mathrm{cm}$-diameter hole $(5.1 \mathrm{~cm}$ above the dowel) in which a peanut could be placed. A .6- $\mathrm{cm}$ colored Velcro ring surrounded the perimeter of the hole, and corresponding Velcro disks, $1.3 \mathrm{~cm}$ in diameter, could be placed over the hole, thereby concealing the contents of the feeder. Feeders were randomly selected for use without replacement until all 91 feeders were used.

\section{Procedure}

Pretraining. The birds were initially trained to eat from a baited feeder and to pull Velcro with the trees and posters absent from the aviary, as described by Brodbeck et al. (1992). Each bird received two to three pretraining trials per day, 6 or 7 days per week, and progressed to the training phase when the sum of the latencies to begin eating in the first phase and to pull on the Velcro in the second phase was less than $1 \mathrm{~min}$ for two of the last three trials.

Training. Training sessions consisted of 3 trials per day with the trees and posters absent. On a given trial, one baited and three nonbaited feeders were placed on a single, randomly selected wall, with each wall used once within each session. The location of feeders and the choice of which feeder was baited was randomly determined. Each trial had two phases. In the study phase, a bird entered the aviary and was allowed to find and to peck at the peanut for $30 \mathrm{sec}$. The lights were then extinguished and the bird returned to its cage for a retention interval, during which Velcro was placed on each feeder. Five minutes after the end of the study phase, the recovery phase began. The bird was allowed to reenter the aviary, remove the Velcro(s), and continue eating for another $30 \mathrm{sec}$ (except for the last recovery phase of each session in which the bird ate until it stopped for $15 \mathrm{sec}$ or left the feeder). Data consisted of the number of looks to find the peanut, defined as a pull that parted the two pieces of Velcro and exposed the hole (confirmed by subsequent inspection). A bird searching randomly was expected to require one, two, three, and four looks to find the peanut equally often. Thus, the mean number of looks to find the peanut at random was 2.5 . Testing began after a minimum of 15 training trials with 7 of the last 9 trials better than chance.

Baseline. The trees and posters were added to the aviary for the remainder of the experiment. Baseline testing consisted of three trials per session, for 15 sessions. Locations were randomly selected on each trial, with the constraint that two walls and two trees each had a feeder. Each trial consisted of a study phase, a 5-min retention interval, and a recovery phase as in training, with an intertrial interval of $29.4 \mathrm{~min}$ ( $S E=.06 \mathrm{~min}$ ). As in training, each bird received the study and test phases for a given item before receiving the next item.

List learning. List-learning test sessions began immediately after baseline sessions were completed. Each session consisted of three sequentially presented study phases $(1,2,3)$, each with different feeders in different configurations, followed by a retention interval and then a test phase for each of the studied configurations. After all 5 birds were exposed to a given configuration, the aviary was set up with the next configuration. The mean interval between study phases was $23.2 \mathrm{~min}(S E=.6 \mathrm{~min})$; the mean interval between Item 3 and the first test phase was $15.8 \mathrm{~min}(S E=.3 \mathrm{~min})$; the mean interval between test phases was $13.5 \mathrm{~min}(S E=.3 \mathrm{~min})$. The order of testing (e.g., 1, 3,2) was randomized in blocks of six sessions. Data were collected for 18 days, 6 or 7 days per week.

\section{Data Analysis}

The data were the number of sites into which birds looked to find the peanut. These data were subjected to repeated measures analyses of variance (ANOVAs) to evaluate variation as a function of serial position. Deviation from chance performance was assessed with the $G$ statistic, which tests for deviation from chance in frequency distributions and has a chi-squared distribution (for details, see Sokal \& Rohlf, 1969, p. 560). The first, second, and third items studied were each tested first only six times. Therefore, to evaluate deviation from chance performance, data from all test positions were pooled for this analysis.

\section{RESULTS}

The mean number of trials to criterion during training was 28.2 (range, 17-41). The mean number of looks required to find the peanut in the last 9 trials was 1.73 $(S D=.23)$. Performance during baseline did not vary as a function of trials $[F(2,8)=1.70]$, as is indicated in Figure 1. Thus, any difference in list-learning performance cannot be due to such factors as satiety, time of day, or number of preceding trials in the session, because these factors did not affect baseline performance. (Note that each baseline datum point in Figure 1 represents performance on the test following each one-item study trial. The data are plotted as a funciton of "serial position" only to facilitate comparison with subsequent performance on the three-item lists.)

Whereas baseline performances did not vary as a function of trials, list-learning performances did show primacy and recency effects. Each bird required fewer looks to find the peanut on the first and third item than on the second item (primacy and recency, respectively), as can be seen in Figure 1. These data were subjected to a repeated measures ANOVA with serial position, tests, and blocks of trials as factors. A significant effect of serial position was observed $[F(2,8)=29.65]$. All other factors and interactions were nonsignificant. It is particularly noteworthy that significant serial position effects were observed on each test $[F(2,8)=19.05,6.03$, and 10.06 , for Tests 1, 2, and 3, respectively]. Subsequent NewmanKeuls statistics for each test revealed that more looks were required for subjects to find the peanut in Serial Position 2 than in Positions 1 and 3, which did not differ.

An alternative measure of performance is percentage of trials on which the peanut was found on the first look (percent correct); chance performance is $25 \%$. Figure 2 shows that this measure provided the same pattern of primacy and recency effects. Arc-sine transformed percent correct scores were subjected to a repeated measures ANOVA with serial position and tests as factors. Again, only a significant serial position effect was observed $[F(2,8)=22.62]$. A subsequent Newman-Keuls statistic revealed that, on the average, percent correct was lower on Serial Position 2 than on Positions 1 and 3, which did not differ from each other. 

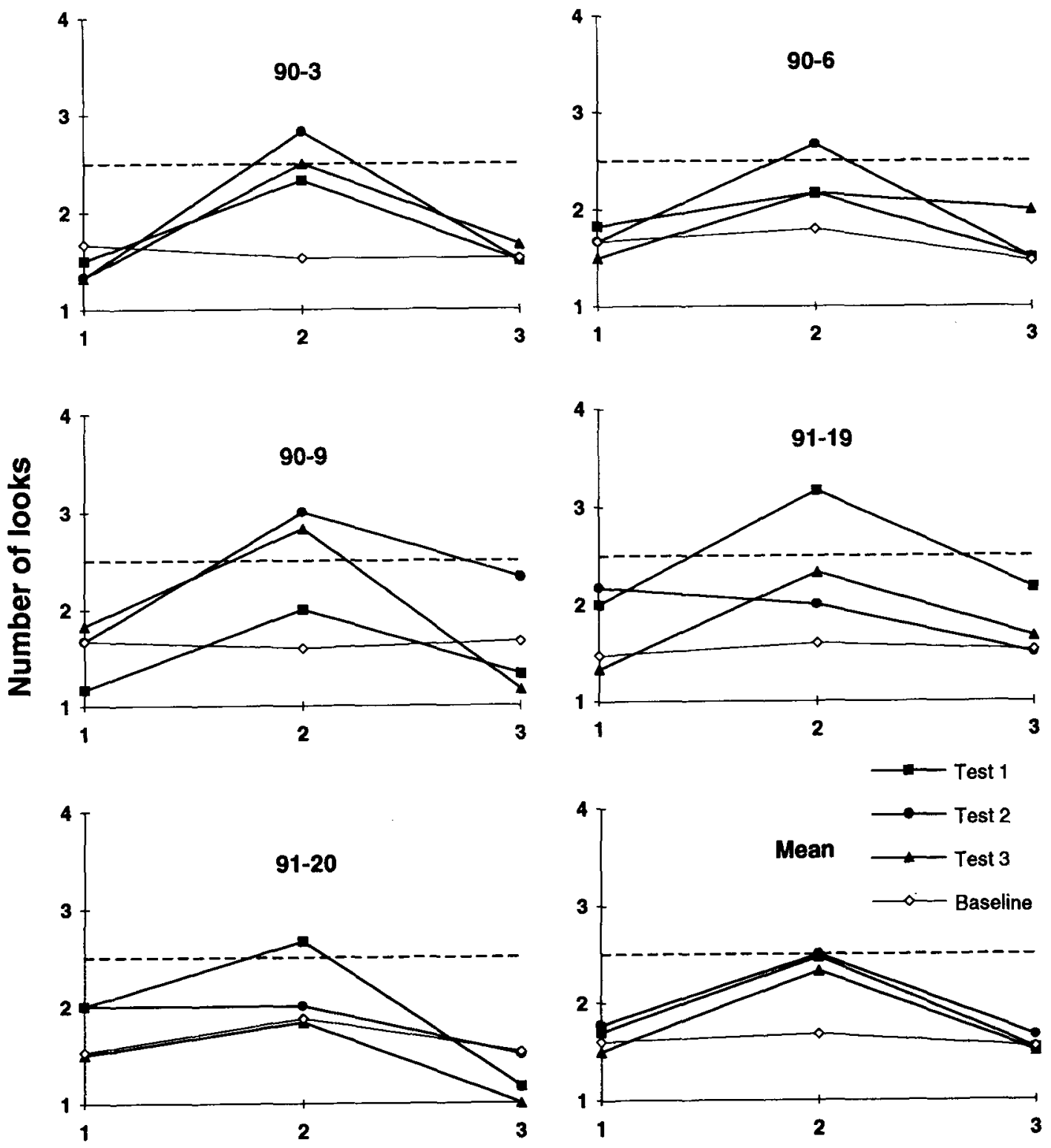

\section{Serial position}

Figure 1. Mean number of looks as a function of serial position from each test for each subject and for the mean. Dashed lines indicate chance performance. In list learning, each bird received each study phase before being tested. In baseline, each bird received the study and test phases for a given item before receiving the next trial.

Frequency distributions of number of looks required to find the peanut, pooled across tests, are shown in Table 1 for individual subjects. In general, each bird performed better than chance on Items 1 and 3 (indicated as $A$ and $C$, respectively, in the table) but at chance on Item 2(B). The only exception to this generalization is that Bird 91-20 was at chance accuracy on both Serial Positions 1 and 2, but better than chance on Position 3 .

\section{DISCUSSION}

We tested for serial position effects in black-capped chickadees with three-item spatial lists, and found both primacy and recency effects. Every bird failed to perform better than chance on the middle item, but only 1 failed to perform better than chance on either the first or the last item. These results suggest that black-capped chick- 

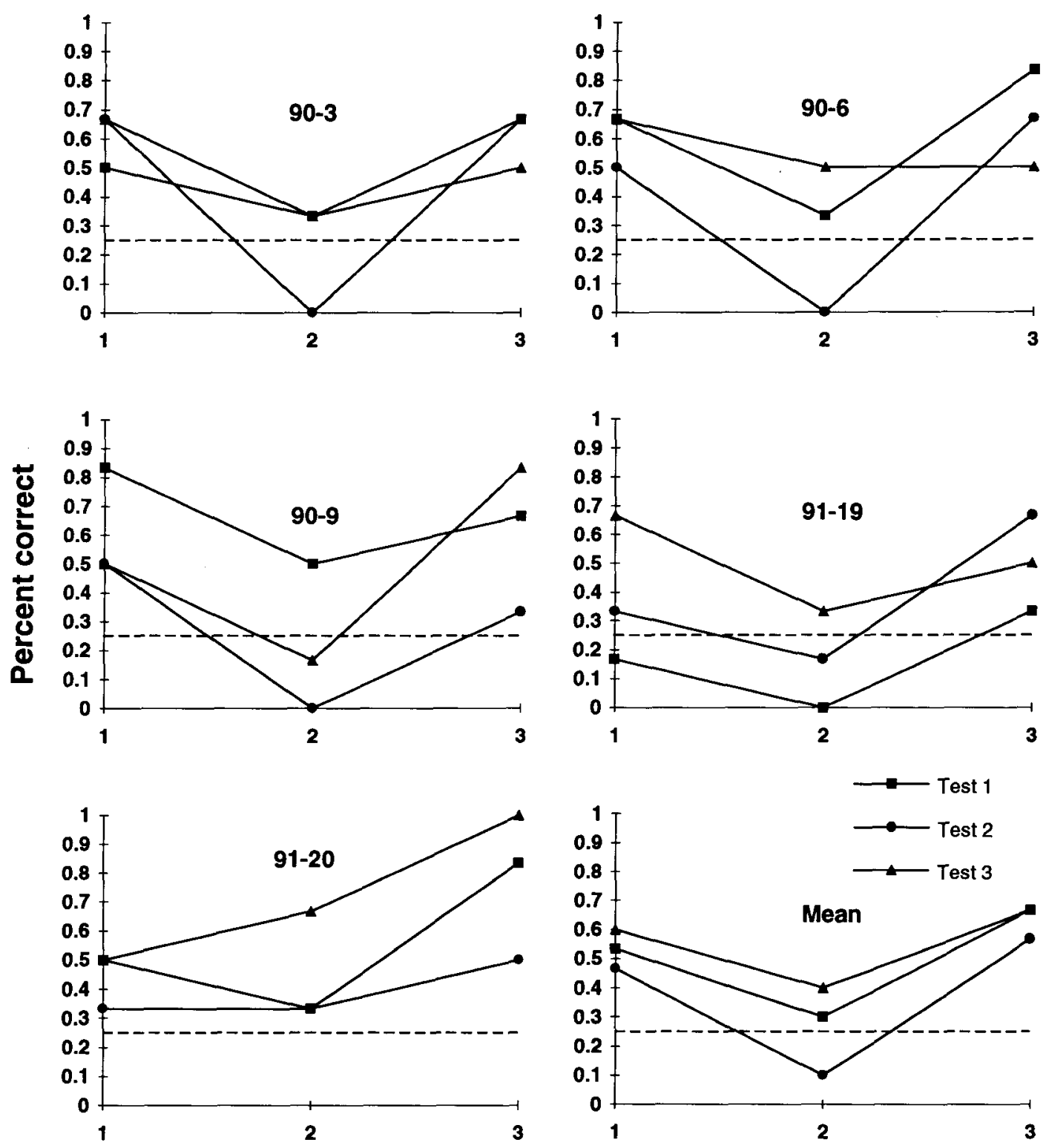

\section{Serial position}

Figure 2. Percent correct as a function of serial position from each test for each subject and for the mean. Dashed lines indicate chance performance. Each bird received each study phase before being tested.

adees are not completely resistant to interitem interference in this task. Additionally, each of three tests following study provided the same pattern of results, indicating that tests did not interfere with memory.

Although resistant to output interference during testing, chickadees apparently are not completely resistant to interitem interference. However, in nature these birds must be competent with many more than just three food locations, which suggests that some factor distinguishes between performance in nature and in the lab. One such factor might be variation among items and types of locations to be remembered. For example, marsh tits choose cache sites that are separated by about $7 \mathrm{~m}$ (Cowie, Krebs, \& Sherry, 1981; Sherry, Avery, \& Stevens, 1982). Cache sites are also distinguished by food types (Sherry, 1984a). By varying caches and cache sites, food-storing birds put themselves in situations in which their memory may be especially efficient.

Gaffan (1992) recently reviewed the literature on serial position effects in animals and concluded that primacy ef- 
Table 1

Frequency Distributions of Number of Looks to Find the Peanut as a Function of Serial Position Pooled Across Tests

\begin{tabular}{|c|c|c|c|c|c|c|}
\hline \multirow[b]{2}{*}{ Bird } & \multirow{2}{*}{$\begin{array}{c}\text { Serial } \\
\text { Position }\end{array}$} & \multicolumn{4}{|c|}{ Number of Looks } & \multirow[b]{2}{*}{$G$} \\
\hline & & 1 & 2 & 3 & 4 & \\
\hline \multirow[t]{3}{*}{$90-3$} & A & 11 & 7 & 0 & 0 & $25.85^{*}$ \\
\hline & B & 4 & 3 & 8 & 3 & 3.40 \\
\hline & $\mathrm{C}$ & 11 & 4 & 3 & 0 & $16.29 *$ \\
\hline \multirow[t]{3}{*}{$90-6$} & A & 11 & 3 & 3 & 1 & $11.79 *$ \\
\hline & B & 5 & 5 & 5 & 3 & .73 \\
\hline & $\mathrm{C}$ & 12 & 2 & 2 & 2 & $13.81 *$ \\
\hline \multirow[t]{3}{*}{$90-9$} & A & 11 & 4 & 3 & 0 & $16.29^{*}$ \\
\hline & B & 4 & 4 & 5 & 5 & .22 \\
\hline & $\mathrm{C}$ & 11 & 4 & 2 & 1 & $12.47^{*}$ \\
\hline \multirow[t]{3}{*}{$91-19$} & A & 7 & 7 & 4 & 0 & $11.43^{*}$ \\
\hline & $\mathbf{B}$ & 3 & 8 & 2 & 5 & 4.58 \\
\hline & $\mathrm{C}$ & 9 & 5 & 3 & 1 & $8.09 *$ \\
\hline \multirow[t]{3}{*}{$91-20$} & A & 8 & 6 & 3 & 1 & 7.22 \\
\hline & B & 8 & 2 & 5 & 3 & 2.17 \\
\hline & $\mathrm{C}$ & 14 & 4 & 0 & 0 & $30.84 *$ \\
\hline \multirow[t]{3}{*}{ Total } & A & 48 & 27 & 13 & 2 & $58.64^{*}$ \\
\hline & B & 24 & 22 & 25 & 19 & .95 \\
\hline & C & 57 & 19 & 10 & 4 & $69.51 *$ \\
\hline
\end{tabular}

Note-Expected frequency is 4.5 for each subject and 22.5 for each total. ${ }^{*} p<.05$.

fects are less pervasive than recency effects and some findings of primacy may be questioned on methodological and statistical grounds. The best evidence for a primacy effect comes from studies of spatial memory (e.g., Bolhuis $\&$ van Kampen, 1988) and from operant studies of picture recognition (e.g., Wright et al., 1985). Hence, our data can be added to those of Bolhuis and van Kampen (1988) as demonstrating a clear primacy effect in a spatial memory task. The fact that our species and procedure were very different from those of Bolhuis and van Kampen and of other investigators strengthens the evidence for primacy as a general feature of list memory in animals (see also Castro \& Larsen, 1992).

This experiment exemplifies the synergistic application of ecological and general process approaches (Kamil, 1988). Ecological considerations motivated the selection of species (a food storer) and the selection of the task (spatial memory) to investigate a general-process phenomenon (serial position effect). The results show that primacy and recency effects can be demonstrated in black-capped chickadees performing a food-finding task with properties similar to that of food-storing. It remains to be determined whether the expression of primacy and recency in food storers depends on retention interval.

\section{REFERENCES}

BAldA, R. P., \& KamIL, A. C. (1989). A comparative study of cache recovery by three corvid species. Animal Behaviour, 38, 486-495.

BAsIL, J. (1992). Neuroanatomical and behavioral correlates of spatial memory in Clark's nutcrackers. Unpublished doctoral dissertation, University of Massachusetts.
Bolhuis, J. J., \& VAN KaMPEN, H. S. (1988). Serial position curves in spatial memory of rats: Primacy and recency effects. Quarterly Joumal of Experimental Psychology, 40, 135-149.

BRODBECK, D. R. (in press). Memory for spatial and local cues: A comparison of a storing and a nonstoring species. Animal Learning \& Behavior.

Brodbeck, D. R., Burack, O. R., \& Shettleworth, S. J. (1992). One-trial associative memory in black-capped chickadees. Journal of Experimental Psychology: Animal Behavior Processes, 18, 12-21.

Castro, C. A., \& LARSEN, T. (1992). Primacy and recency effects in nonhuman primates. Journal of Experimental Psychology: Animal Behavior Processes, 18, 335-340.

Cowie, R. J., Krebs, J. R., \& Sherry, D. F. (1981). Food storing by marsh tits. Animal Behaviour, 29, 1252-1259.

Crowder, R. G. (1976). Principles of learning and memory. Hillsdale, NJ: Erlbaum.

GafFan, E. A. (1992). Primacy, recency, and the variability of data in studies of animals' working memory. Animal Learning \& Behavior, 20, 240-252.

HEALY, S. D., \& KREBS, J. R. (1992). Comparing spatial memory in two species of tit: Recalling a single positive location. Animal Learning \& Behavior, 20, 121-126.

HILTON, S. C., \& KREBS, J. R. (1990). Spatial memory of four species of Parus: Performance in an open-field analogue of a radial maze. Quarterly Journal of Experimental Psychology, 42B, 345-368.

Hiтch, G. J. (1985). Short-term memory and information processing in humans and animals: Towards an integrative framework. In L.-G. Nilsson \& T. Archer (Eds.), Perspectives on learning and memory (pp. 119-136). Hillsdale, NJ: Erlbaum.

HitchCock, C. L., \& SHeRRY, D. F. (1990). Long-term memory for cache sites in the black-capped chickadee. Animal Behaviour, 40, 701-712.

KamIL, A. C. (1988). A synthetic approach to the study of animal intelligence. In D. W. Leger (Ed.), 1987 Nebraska Symposium on Motivation (Vol. 35, pp. 257-308). Lincoln: University of Nebraska Press.

Kamil, A. C., \& Balda, R. P. (1990a). Differential memory for different cache sites by Clark's nutcrackers (Nucifraga columbiana). Journal of Experimental Psychology: Animal Behavior Processes, 16, 162-168.

KamiL, A. C., \& BALDA, R. P. (1990b). Spatial memory in seed-caching corvids. Psychology of Learning \& Motivation, 26, 1-25.

Kamil, A. C., Balda, R. P., Olson, D. J., \& Good, S. (1993). Returns to emptied cache sites by Clark's nutcrackers (Nucifraga columbiana). Animal Behaviour, 45, 241-252.

OLSON, D. J. (1991). Species differences in spatial memory among Clark's nutcrackers, scrub jays, and pigeons. Journal of Experimental Psychology: Animal Behavior Processes, 17, 363-376.

Santiago, H. C., \& Wright, A. A. (1984). Pigeon memory: Same/different concept learning, serial probe recognition acquisition, and probe delay effects on serial-position function. Journal of Experimental Psychology: Animal Behavior Processes, 10, 498-512.

SHERRY, D. F. (1982). Food storage, memory, and marsh tits. Animal Behaviour, 30, 631-633.

SHERRY, D. F. (1984a). Food storage by black-capped chickadees: Memory for the location and contents of caches. Animal Behaviour, 32, $451-464$

SherRY, D. F. (1984b). What food-storing birds remember. Canadian Joumal of Psychology, 38, 304-321.

Sherry, D. [F.], AVERY, M., \& Stevens, A. (1982). The spacing of stored food by marsh tits. Zeitshrift für Tierpsychologie, 58, 153-162.

SHETTLEWORTH, S. J. (1985). Food storing by birds: Implications for comparative studies of memory. In J. L. McGaugh \& G. Lynch (Eds.), Memory systems of the brain (pp. 231-250). New York: Guilford. SHETTlewORTH, S. J. (1990). Spatial memory in food-storing birds. Philosophical Transactions of the Royal Society of London: Series B, 329, 143-151.

SHETTLEWORTH, S. J. (1993). Where is the comparison in comparative cognition? Alternative research programs. Psychological Science, 4, 179-184. 
Shettleworth, S. J., \& KREBS, J. R. (1982). How marsh tits find their hoards: The role of site preference and spatjal memory. Journal of Experimental Psychology: Animal Behavior Processes, 8, 354-375.

ShetTleworth, S. J., Krebs, J. R., Healy, S. D., \& Thomas, C. M. (1990). Spatial memory of food-storing tits (Parus ater and $P$. atricapillus): Comparison of storing and nonstoring tasks. Journal of Comparative Psychology, 104, 71-81.

Sokal, R. R., \& RohlF, F. J. (1969). Biometry. San Francisco: W. H. Freeman.

StadDon, J. E. R. (1989). Animal psychology: The tyranny of anthropocentrism. Perspectives in Ethology, 8, 123-135.
Vander Wall, S. B. (1990). Food hoarding in animals. Chicago: University of Chicago Press.

WRIGHT, A. A. (1989). Memory processing by pigeons, monkeys, and people. Psychology of Learning \& Motivation, 24, 25-70.

Wright, A. A., Santiago, H. C., Sands, S. F., Kendrick, D. F., \& CoOK, R. G. (1985). Science, 229, 287-289.

(Manuscript received February 2, 1993; revision accepted for publication May $7,1993$. ) 